\title{
Expression of Estrogen Receptor $\beta$ in Colon Cancer Progression
}

\author{
Francesca Castiglione, MD, ${ }^{*}$ Antonio Taddei, MD, $\dagger$ Duccio Rossi Degl'Innocenti, BSc, ${ }^{*}$ \\ Anna Maria Buccoliero, PhD, ${ }^{*}$ Paolo Bechi, MD, $\dagger$ Francesca Garbini, MD,* \\ Francesca Gheri Chiara, MD,* Daniela Moncini, PhD,* Giulia Cavallina, MD, $\dagger$ \\ Lavinia Marascio, MD, $\dagger$ Giancarlo Freschi, MD, $\dagger$ and Luigi Taddei Gian, MD*
}

\begin{abstract}
Colon cancer is the most frequent neoplasia of the intestine. This pathology is the third highest cause of death from cancer with 430,000 deaths globally per year. Estrogen has also been implicated in the development and progression of colon cancer. Also sex-specific differences have been suggested to be involved in the process. Previous studies have shown the estrogen $\beta$ receptor to be the dominant receptor type in normal colonic tissue and its down-regulation along with the progression of colorectal cancer. The presence of estrogen receptors and products of estrogen-related genes in the colon suggests that estrogens have direct effects on the colonic tissue. However, the specific effect of estrogens on a normal colon and the role in the colon carcinogenesis are far from clear. The aim of this study is to analyze by real-time polymerase chain reaction, the relative quantitative expression of the estrogen receptors $\beta, \beta 1, \beta 2$, and $\beta 5$ in colon adenocarcinomas and to compare this expression with the respective in normal tissues. Moreover, we evaluate a possible correlation between estrogen's receptor expressions and disease stages. Normal tissues show estrogen receptor $\beta$ expression greater than pathologic tissues and the estrogen receptor $\beta$ result as most expressed in the lower disease stages.
\end{abstract}

Key Words: estrogen receptor, colon cancer, real-time PCR, expression

(Diagn Mol Pathol 2008;17:231-236)

C olon cancer (CC) is the third leading cause of cancer deaths with an estimated 430,000 deaths per year world-wide. ${ }^{1}$ The prognosis is dependent on the stage of the disease at the time of diagnosis, and the mean 5-year survival rate is relatively poor in most cases. ${ }^{2}$ Evidence for a dual role of estrogens in gastrointestinal physiology is accumulating with the high incidence of CC. Age and sex differences in the incidence of gastrointestinal tumors

From the Departments of *Human Pathology and Oncology; and $\dagger$ Surgical Pathology, School of Medicine, University of Florence, Florence, Italy.

Reprints: Francesca Castiglione, MD, Department of Human Pathology and Oncology, School of Medicine, University of Florence, Viale GB Morgagni, 85. 50134 Florence, Italy (e-mail: francesca.castiglione@ unifi.it).

Copyright (C) 2008 by Lippincott Williams \& Wilkins suggest the involvement of sex steroids. The age adjusted incidence rate is higher in men than in women ${ }^{1}$ and the protective effect of female hormones is evident in a number of studies. In addition to their effects on sexual development and reproductive functions, the cardiovascular system, the central nervous systems, and bone, both exogenous and endogenous estrogens exert significant effects on gastrointestinal physiology. ${ }^{3}$ Estrogens have also been implicated in the development and progression of $\mathrm{CC}^{3}$ and sex-specific differences have been suggested to be involved in the process. ${ }^{4}$ The lifetime risk seems to be significantly lower and the survival rates better ${ }^{5}$ in females than in males. Epidemiologic studies have demonstrated that colorectal cancer incidence and mortality rates are lower in women than men. ${ }^{3}$ Many studies indicate that estrogen replacement therapy (ERT) exerts a protective role against $\mathrm{CC}$ in postmenopausal women. ${ }^{4}$ The steroid hormone $17 \beta$-estradiol (E2) is a critical regulator of growth, differentiation, and function in a wide range of target tissues. The main biologic functions of E2 are mediated through 2 distinct intracellular receptors, ER $\alpha$ (estrogen receptor $\alpha$ ) and $\operatorname{ER} \beta$ (estrogen receptor $\beta$ ). ${ }^{5}$ The ERs mainly act as ligand-activated transcription factors and they modulate gene expression by interactions with promoter response elements or other transcription factors. ${ }^{6}$ In addition to this classic ligand-dependent pathway, ER function may also be modulated by extracellular signals in the absence of E2 or a ligandindependent manner. ${ }^{7,8}$

ERs are members of the evolutionary conserved nuclear receptor superfamily of ligand-inducible transcription factors. ER $\alpha$ and ER $\beta$ exhibit a modular structure consisting of 6 well-defined functional domains (A-F). ${ }^{9}$ Unliganded ERs reside in multiprotein complexes located in the nucleus. Estrogen binding to the "ligand binding domain" induces a conformational change that facilitates receptor homodimerization $(E R \alpha / E R \alpha$ or $E R \beta / E R \beta)$ or heterodimerization $(E R \alpha / E R \beta)$ and highaffinity binding to specific DNA recognition sequences [estrogen response elements (EREs)] in the regulatory regions of estrogen target genes. In this "classic" mode of ER action, ER $\alpha$ and ER $\beta$ homodimers promote ERE-regulated transcription in response to $17 \beta$-estradiol, with ER $\beta$ being approximately $30 \%$ as efficient as ER $\alpha$ in most cell systems. Estrogens and their cognate receptors 
also regulate target genes via a "nonclassic" mode of action. These effects are mediated through promoter elements that bind heterologous transcription factors, including activating protein-1 (AP-1)-binding sites, cyclic AMP response elements (CREs), antioxidant elements and SP-1-binding sites.

Interestingly, ER $\alpha$ and $E R \beta$ can exert opposite actions at AP-1 sites in the presence of different ligands. $17 \beta$-estradiol increases ER $\alpha / \mathrm{AP}-1$-mediated transcription, but represses ER $\beta / \mathrm{AP}-1$ effects, whereas antiestrogens like tamoxifen enhance AP-1-induced transcription through both ERs. ${ }^{10,11}$ It is evident that in both the "classic" and "nonclassic" mode of ER action, ER $\beta$, in the presence of estrogen, modulates the proliferating effects of $E R \alpha$ by suppressing transcriptional activation. Thus, ER $\beta$ may protect the cell from uncontrolled proliferation and malignant transformation. Consistent with this notion, a progressive decline of ER $\beta$ expression has been reported in multistage mammary carcinogenesis $^{12}$ and in prostate cancer. ${ }^{13}$

Epidemiologic studies have demonstrated that colorectal cancer incidence and mortality rates are lower in women than in men. ${ }^{14}$ Many studies indicate that ERT exerts a protective role against $\mathrm{CC}$ in postmenopausal women. ${ }^{15}$ According to a meta-analysis, recent use of ERT is associated with a $33 \%$ reduction of CC risk and the relative risk for death from CC in ERT users is 0.72 , whereas rectal cancer incidence is not associated with ERT. ${ }^{16}$

$\mathrm{ER} \alpha$, previously regarded as the sole ER, is minimally expressed in normal and cancerous colons. ${ }^{17,18}$ ER $\beta$ mRNA has been detected in normal colonic mucosa by the real-time polymerase chain reaction (RT-PCR) and subsequent southern analysis, ${ }^{17}$ whereas ER $\beta$ protein expression has been documented in the normal colon tissue by Western immunoblotting. ${ }^{19}$ No expression of ER $\beta$ in colon adenocarcinoma was reported in this Western-blot analysis, ${ }^{19}$ whereas an immunohistochemical study in $55 \mathrm{CC}$ patients has demonstrated ER $\beta$ expression. ${ }^{20}$

The aim of the present study was to assess the importance of ER $\beta$ and its isoforms $\beta 1, \beta 2$, and $\beta 5$ in colon adenocarcinoma by investigating its mRNA expression levels in a well-defined patient cohort. We also sought to correlate its expression with clinical-pathologic features.

\section{MATERIALS AND METHODS}

\section{Patients}

Colonic mucosa fragments from 40 consecutive patients (24 men, 16 women, mean age 73 ) were obtained by cold blade cut from the operative specimens of patients undergoing colon resection for cancer. Specimens were taken at least $10 \mathrm{~cm}$ far away from the neoplasm, and colon mucosa appeared normal at macroscopic evaluation. Patients did not receive preoperative radiotherapy or chemotherapy and were treated at the Surgical Pathology 1, University of Firenze.
All samples were microscopically evaluated and classified as colon adenocarcinoma and normal colonic mucosa.

All tissue pieces were sectioned to ensure that all spatial dimensions were $\leq 10 \mathrm{~mm}(10 \times 10 \times 0.3 \mathrm{~mm})$. All diagnoses were confirmed by examination of $5-\mu \mathrm{m}$ hematoxylin and eosin-stained sections and all colonic mucosa fragments resulted macroscopically and histologically whole. The fragments were immersed in RNAlater (Qiagen, Milan, Italy) and kept overnight at $4{ }^{\circ} \mathrm{C}$ and stored at $-80^{\circ} \mathrm{C}$ until analyzed.

\section{RNA Isolation}

The tissues (about $5 \mathrm{mg}$ ) were defrosted and cut into small pieces. The samples were resuspended in $200 \mu \mathrm{L}$ Nucleic Acid Purification Lysis Solution (Applied Biosystems, Foster City, CA) and homogenized using PCR Tissue Homogenizing Kit (PBI International, Milan, Italy) in microcentrifuge tubes. RNA was isolated using 6100 Nucleic Acid PrepStation (Applied Biosystems, Foster City, CA) and successively stored at $-80^{\circ} \mathrm{C}$.

\section{Real-time Quantitative PCR}

All RNA samples (200 ng) were reverse transcribed to cDNA using iScript Select cDNA Synthesis Kit (Bio-Rad Laboratories, Hercules, CA) according to the manufacturer's protocol. In the real-time reaction, negative control was performed.

TaqMan real-time quantitative PCR was performed on an ABI PRISM 7000 Sequence Detector System (Applied Biosystems). PCR products for ER $\beta$ gene was detected using gene-specific primers and probes labeled with reporter day FAM (Assay on Demand, Applied Biosystems, Foster City, CA). PCR products for ER $\beta 1$, ER $\beta 2$, and ER $\beta 5$ genes were detected using 4 primers and a probe designed with Primer Express software (Applied Biosystems). The primers used for the ER $\beta 1$ gene expression consisted of "ER $\beta$-universal" (5'-GCCTGG CTAACCTCCTGATG-3'; forward) and "ER $\beta 1 D$ " (5'TTCATGTTGAGCAGATGTTCCAT-3'; reverse); for the ER $\beta 2$ gene the primers consisted of "ER $\beta$-universal" and "ER $\beta 2 \mathrm{D}$ " (5'-TCCAAATGAGGTGAGTGTTTG AGA-3'; reverse). The primers for the ER $\beta 5$ gene were "ER $\beta$-universal" and "ER $\beta 5 D "$ (5'-AGACACTTTTCC CAAATCACTTCAC-3'; reverse). The probe (6-FAMTGTCCCACGTCAGGCA-MGB) is labeled with reporter day FAM. Glyceraldehyde-3-phosphate dehydrogenase gene was used as an endogenous control gene for normalization and was detected using gene-specific primers and probes labeled with reporter day VIC (Applied Biosystems).

PCR reaction was carried out in triplicate on 96-well plate with $20 \mu \mathrm{L}$ per well using $1 \times$ TaqMan Universal PCR MasterMix. After incubating for 2 minutes at $50^{\circ} \mathrm{C}$ and 10 minutes at $95^{\circ} \mathrm{C}$, the reaction continues for 50 cycles at $95^{\circ} \mathrm{C}$ for 15 seconds and $60^{\circ} \mathrm{C}$ for 1 minute. 


\section{Analysis of Results}

At the end of the reaction, the results were evaluated using the ABI 7000 PRISM software and the Ct values were exported to Microsoft Excel.

The $2^{-\Delta \Delta \mathrm{Ct}}$ method described by Livak and Schmittgen $^{21}$ was used to analyze the results. The $\mathrm{Ct}$ values for each set of 3 reactions were averaged for all subsequent calculations. For each sample of $\mathrm{CC}$, the specimen of normal colonic mucosa from the same patient was used as a control sample.

\section{Statistical Analysis}

The shift of relative expression level of genes in $\mathrm{CC}$ and normal colonic mucosa was calculated according to the Wilcoxon test. Data analysis was performed using the SPSS Version 14.0 (Chicago, IL) statistical package. A $P$ value $\leq 0.05$ was considered to be statistically significant.

\section{RESULTS}

We analyzed 80 samples from 40 consecutive patients: a specimen from colon adenocarcinoma and a specimen from normal mucosa for each patient.

Twenty samples were tumors of sigma and 20 were tumors of rectum. All colon adenocarcinoma samples were classified according to Dukes classification: 5 had Dukes A stage disease, 17 had Dukes B stage disease, 13 had Dukes C stage disease, and 5 had Dukes D stage disease (Table 1).

We successfully extracted RNA from all samples. The RNA concentration and purity were quantitated spectrophotometrically by measuring their absorbance at 260 and $280 \mathrm{~nm}$. For each patient, the expression of each gene in $\mathrm{CC}$ was compared with the expression in normal colonic mucosa.

$\mathrm{ER} \beta$ gene expression was present in $38 \mathrm{CCs}$ and in 38 normal mucosa (in a case, it is absent in both of them). Thirty-one of thirty-seven tumor samples expressed the ER $\beta$ gene lower than normal mucosa. The mean of this gene expression in the CCs was $97 \%$ lower compared with the expression in normal mucosa in cases that express it in both of them $(P<0.001)$ (Fig. 1).

ER $\beta 1$ expression has been shown in $80 \%$ of adenocarcinomas (32 cases) and in $87 \%$ of normal mucosae ( 35 cases): in 3 cases, it is absent in both. The mean of ER $\beta 1$ expression in tumor tissue was $89 \%$ lower compared with normal colonic mucosa; 6 tumor samples expressed higher than normal mucosa (maximum: 1.7 times higher), and 24 cases showed lower expression (maximum: 2.7 times lower $)(P<0.001)$ (Fig. 2).

ER $\beta 2$ gene is expressed in all samples except $1 \mathrm{CC}$ and 2 normal mucosae. Thirty-two cases $(89 \%)$ showed lower expression in CC compared with normal mucosa, with an expression range from 3.8 times lower to 0.8 times higher $(P<0.001)$ (Fig. 3).

The expression of ER 35 gene is present in all specimens. For this gene, 18 tumor cases showed an expression higher than the normal mucosa (maximum: 3.5

\begin{tabular}{|c|c|c|c|}
\hline Patient & Sex & Stage & Site \\
\hline 1 & $\mathrm{~F}$ & A & Sigma \\
\hline 2 & M & B & Sigma \\
\hline 3 & F & C & Rectum \\
\hline 4 & M & $\mathrm{C}$ & Sigma \\
\hline 5 & $\mathrm{~F}$ & A & Rectum \\
\hline 6 & F & B & Sigma \\
\hline 7 & M & D & Sigma \\
\hline 8 & $\mathrm{~F}$ & C & Rectum \\
\hline 9 & M & B & Rectum \\
\hline 10 & M & $\mathrm{C}$ & Sigma \\
\hline 11 & M & B & Rectum \\
\hline 12 & M & B & Sigma \\
\hline 13 & $\mathrm{~F}$ & B & Rectum \\
\hline 14 & $\mathrm{~F}$ & D & Rectum \\
\hline 15 & F & B & Sigma \\
\hline 16 & M & A & Rectum \\
\hline 17 & M & B & Sigma \\
\hline 18 & M & D & Rectum \\
\hline 19 & $\mathrm{~F}$ & $\mathrm{C}$ & Sigma \\
\hline 20 & M & B & Sigma \\
\hline 21 & M & C & Sigma \\
\hline 22 & M & B & Rectum \\
\hline 23 & M & B & Rectum \\
\hline 24 & F & C & Rectum \\
\hline 25 & M & $\mathrm{C}$ & Rectum \\
\hline 26 & M & D & Sigma \\
\hline 27 & $\mathrm{~F}$ & $\mathrm{C}$ & Rectum \\
\hline 28 & $\mathrm{~F}$ & B & Rectum \\
\hline 29 & M & $\mathrm{C}$ & Sigma \\
\hline 30 & F & B & Sigma \\
\hline 31 & $\mathrm{~F}$ & A & Sigma \\
\hline 32 & $\mathrm{~F}$ & B & Rectum \\
\hline 33 & M & C & Sigma \\
\hline 34 & M & B & Rectum \\
\hline 35 & M & D & Sigma \\
\hline 36 & M & $\mathrm{C}$ & Sigma \\
\hline 37 & M & B & Rectum \\
\hline 38 & M & $\mathrm{C}$ & Rectum \\
\hline 39 & $\mathrm{~F}$ & B & Sigma \\
\hline 40 & $\mathrm{~F}$ & A & Rectum \\
\hline
\end{tabular}

Sex and sites from where the specimens were resected for analyses, and tumor stages at operation, according to the Dukes classification.

times higher), whereas 22 cases showed lesser expression (maximum: 3.7 times lower); the mean of ER $\beta 5$ gene expression was $8 \%$ lower in cancer tissues compared with normal mucosa $(P=0.667)$ (Fig. 4).

The expression of $\beta, \beta 1, \beta 2$, and $\beta 5$ ERs were evaluated in relation to Dukes classification. The patients were divided into 2 groups: the first group included patients with Dukes A and B disease stages and the second group with patients with Dukes $\mathrm{C}$ and $\mathrm{D}$ disease stages.

There were $21(51 \%)$ patients in the first group and $19(49 \%)$ in the second group. The expression means of all ER $\beta$ was higher in the cases with Dukes A and $\mathrm{B}$ stages compared to the cases with $\mathrm{C}$ and $\mathrm{D}$ stages $(P=0.068)$ (Fig. 5).

\section{DISCUSSION}

$\mathrm{CC}$ is the most frequent neoplasia of the intestine. This pathology is the third highest cause of death by 


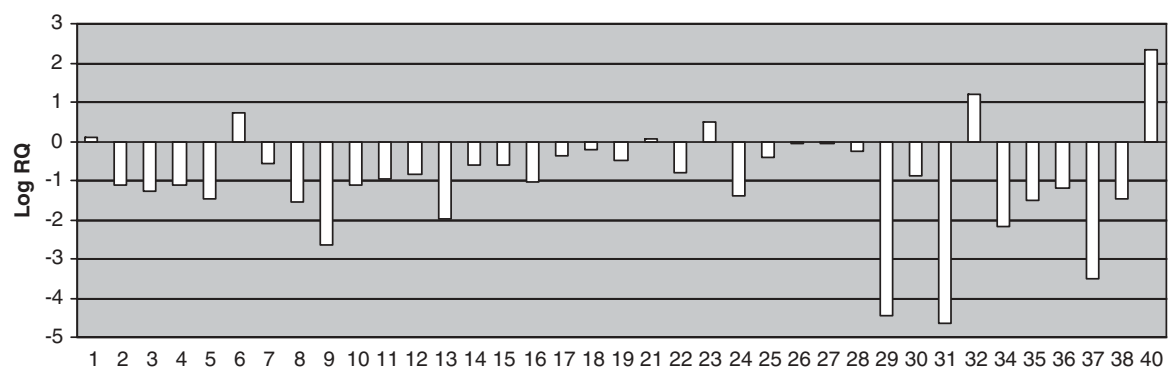

FIGURE 1. Relative expression of ER $\beta$ gene in colon adenocarcinoma compared with normal colon mucosa. The graphic displays only the cases which shows expression in both, colon adenocarcinoma and normal colon mucosa.

cancer with 350,000 new cases diagnosed every year in Europe and 430,000 deaths globally. ${ }^{1}$

Estrogens are members of the steroidal hormone family and their precursor is the cholesterol (locally synthesized) ex novo or obtained from low-density lipoproteins circulating. The steroidal hormones are not kept in the secreting cell but enter directly in the blood stream. The majority of steroidal hormones are associated with specific transport proteins and only a small fraction of hormones are present in blood circulation. This fraction of biologically active proteins influence the response of the target cell and the secretion down-regulation through feedback mechanisms. Estrogen synthesis is regulated by the pituitary-hypothalamic axis, which is the center of a sophisticated network of connections between nervous, immune, and endocrine systems.

Estrogens act upon different signaling pathways: a "classic genomic way," which activates target genes and a "nongenomic way," which activates a fast modulation of intracellular second messengers (without protein synthesis).

Estrogen effects are mediated by the 2 ERs, ER $\alpha$ and $\operatorname{ER} \beta$, both of which are present in colorectal tissues and cell lines. ${ }^{1,17,19,22}$ Previous studies have shown ER $\beta^{23}$ to be the dominant receptor type in normal colonic tissue, and its down-regulation during the progression of colorectal cancer. ${ }^{1,17,19}$ Issa et $\mathrm{l}^{22}$ suggested that methylationassociated inactivation of the ER tumor suppressor gene in aging colorectal mucosa could predispose to CC. The discovery of ERs and products of estrogen-related genes in the colon suggests that estrogens have direct effects on the colonic tissue. However, the specific effect of estrogens on a normal colon and its role in the colon carcinogenesis are far from clear.

The presence of ER $\beta$ was first demonstrated in 1996. ${ }^{24}$ Since then, at least 5 splice variant isoforms of the ER $\beta$ gene product (ER $\beta 1$ to $\operatorname{ER} \beta 5)$ have been described. ${ }^{25}$ ER $\beta 1$, ER $\beta 2$, and ER $\beta 5$ have been demonstrated in normal colorectal mucosa and at much higher levels than ER $\alpha \cdot{ }^{17,19}$ Of these 3 isoforms, only the full-length ER $\beta$ protein, equivalent to the ER $\beta 1$ isoform described by Moore and colleagues, ${ }^{25}$ can activate estrogen-responsive elements in reporter assays. ${ }^{26}$ Many of the ways in which "ER $\beta$ " has, thus far, been reported to mediate estrogenic activity are likely to represent ER $\beta 1$-based activation. Less is known of the functions of the other ER $\beta$ isoforms. However, ER $\beta 2$ (also known as ER $\beta c x)$ shows different and potentially opposing activities to ER $\beta 1$ regarding binding of ligand and of ERE and non-ERE containing promoters. ${ }^{26}$ There is little available data regarding the function of ER $\beta 5$.

The tissue expression of the 2 estrogenic receptors shows a considerable specificity. The ER $\alpha$ preponderate in the uterus, the liver, the skeletal muscle, the adipose tissue, the hypophysis, and the hypothalamus, and the ER $\beta$ is the principal ER in the ovary, the prostate, and in specific cerebral regions (limbic system, cerebellum, and cortex).

In conclusion, the regulation of target genes expression in the different tissues depends on the ligand

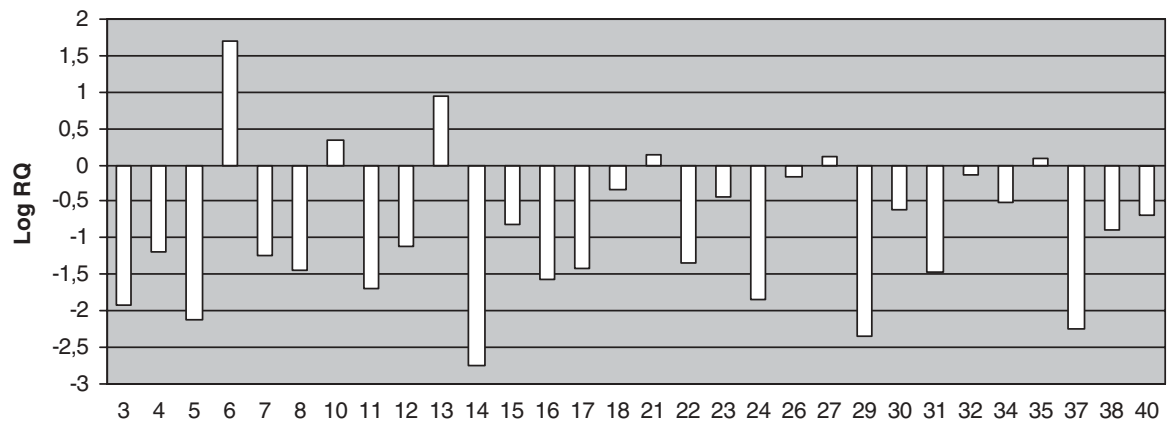

FIGURE 2. Relative expression of ER $\beta 1$ gene in colon adenocarcinoma compared with normal colon mucosa. The graphic displays only the cases that show expression in both colon adenocarcinoma and normal colon mucosa. 


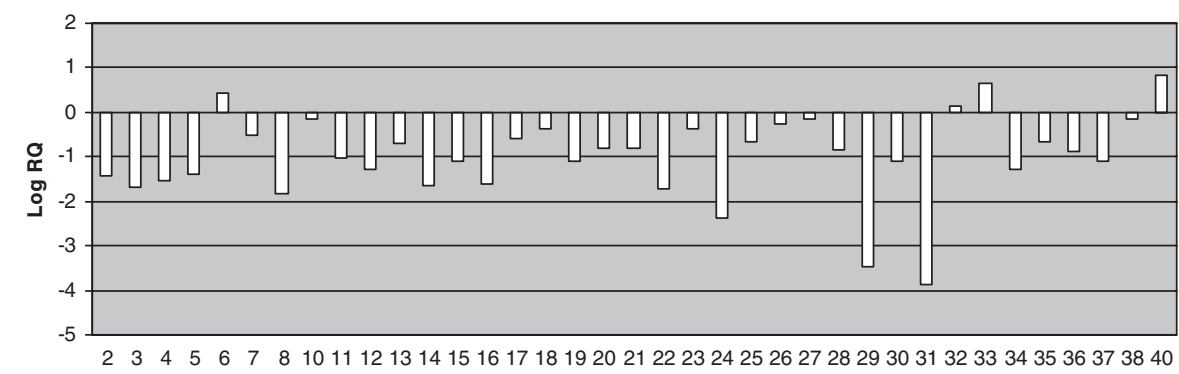

FIGURE 3. Relative expression of ER $\beta 2$ gene in colon adenocarcinoma compared with normal colon mucosa. The graphic displays only the cases that show expression in both colon adenocarcinoma and normal colon mucosa.

kind, on the relative distribution of 2 estrogenic receptors, on the promoter type, and on the intracellular action mechanism of the ligand, but also on the dimerization type between the 2 receptors.

Formerly, the estrogens have been considered hormones of the female reproductive system, but in the last few years, the role of these hormones in development and control of the male reproductive system seems more and more evident.

The aim of this study is to analyze by real-time PCR the relative quantitative expression of the estrogens $\beta, \beta 1$, $\beta 2$, and $\beta 5$ receptors in colon adenocarcinomas and compare this expression with the same in normal tissues. Moreover, we observed a possible correlation between ER expressions and disease stages.

The ERs showed uniform and statistically significant $(P<0.003)$ expression both in adenocarcinoma fragments and in normal mucosae. Normal tissues showed a receptor expression greater than pathologic tissues, and the ER $\beta s$ were most expressed in the lower disease stages.

The literature is inadequate regarding this subject. We hypothesize these receptors have a possible protecting role in colon mucosa regarding cellular turn-over during tumor development derived from p53 control loss on the cellular cycle.

There is no doubt about the role of p53 mutations in the progression of colorectal tumors. Overexpression of exogenous $\mathrm{p} 53$, DNA-damaging agents that activate endogenous $\mathrm{p} 53$, also resulted in reduced $\beta$-receptor in wild-type p53-containing tumor cell lines. The degradation signal controlling $\beta$-receptor levels is inducible by p53, revealing a link between genotoxic injury responses and $\beta$-receptor degradation. ${ }^{27}$

In conclusion, ER $\beta$ is highly expressed in normal colonic mucosa. Colon adenocarcinoma cells display significantly lower ER $\beta$ expression, which parallels the loss of their differentiation.

Cancers of the proximal and distal colon may have different underlying mechanisms, but the decline of ER $\beta$ expression is independent from the tumor localization. ${ }^{28}$ Because ER $\beta$ is the dominant ER in normal colonic mucosa, these data can suggest a probable role for ER $\beta$ in preventing the malignant transformation of colonic epithelial cells. If these data, for now not statistically significant, are confirmed, selective ER $\beta$ agonists could become important in CC chemoprevention. Moreover, they could be of interest to evaluate the smaller expression trend of ER $\beta$ genes in the advanced adenocarcinomas stages (according to Dukes staging), and if correlated with the other data in this study, could be an ulterior support of the loss of ERs expression in development and progression of colon pathology.

The distribution of ER $\beta 5$ isoform expression seems interesting because it is most expressed in normal tissue in only $50 \%$ of the cases, unlike the isoforms $\mathrm{ER} \beta, \mathrm{ER} \beta 1$, and ER $\beta 2$ (even if these 3 isoforms present $15 \%$ of the cases in which the genic expression is greater in the tumor than in the healthy mucosa). They could be extremely important in considering how estrogens are not exclusively a protecting factor in colon cancerogenesis but also a possible risk factor as evidenced in the mammary cancer. ${ }^{29,30}$

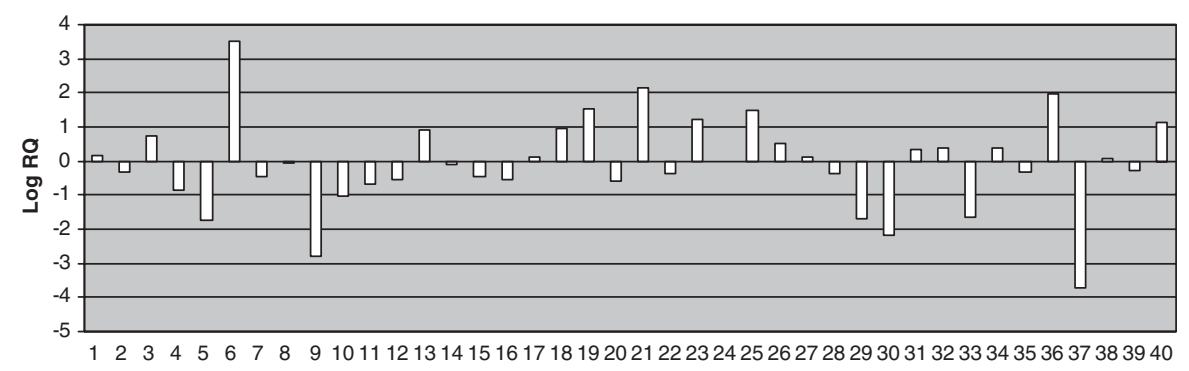

FIGURE 4. Relative expression of ER $\beta 5$ gene in colon adenocarcinoma compared with normal colon mucosa. The graphic displays only the cases that show expression in both colon adenocarcinoma and normal colon mucosa. 


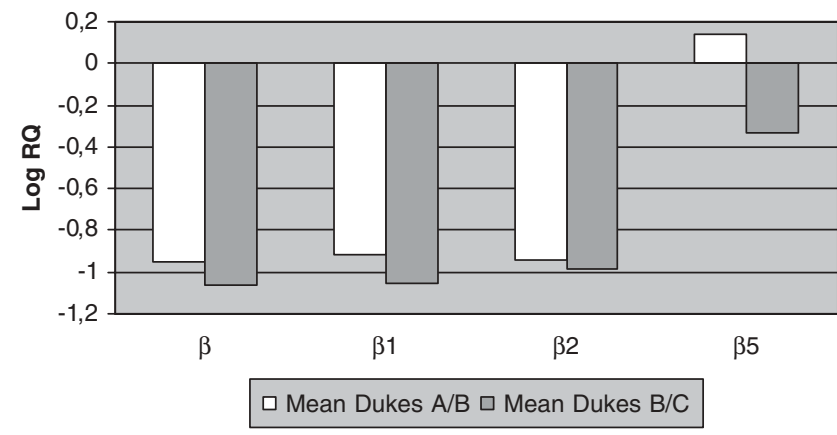

FIGURE 5. Mean of relative expression of all ER $\beta$ genes in colon adenocarcinoma compared with normal colon mucosa, subdivided by Dukes stages. The white columns represent the patients with Dukes A and B disease stages and the gray columns represent the patients with Dukes $C$ and D disease stages.

Considering the literature, these data results are original. However, because of the insufficient sample number, further conclusions are not possible at this moment and we evidence only the different biologic behavior of ER $\beta 5$.

\section{REFERENCES}

1. Oduwole OO, Makinen MJ, Isomaa VV, et al. 17Beta-hydroxysteroid dehydrogenase type 2: independent prognostic significance and evidence of estrogen protection in female patients with colon cancer. $J$ Steroid Biochem Mol Biol. 2003:87:133-140.

2. Makela JT, Laitinen SO, Kairaluoma MI. Five-year follow-up after radical surgery for colorectal cancer.Results of a prospective randomized trial. Arch Surg. 1995;130:1062-1067.

3. English MA, Stewart PM, Hewison M. Estrogen metabolism and malignancy: analysis of the expression and function of 17betahydroxysteroid dehydrogenases in colonic cancer. Mol Cell Endocrinol. 2001;171:53-60.

4. Singh S, Sheppard MC, Langman MJ. Sex differences in the incidence of colorectal cancer: an exploration of oestrogen and progesterone receptors. Gut. 1993;34:611-615.

5. Froggatt NJ, Green J, Brassett C, et al. A common MSH2 mutation in English and North American HNPCC families: origin, phenotypic expression, and sex specific differences in colorectal cancer. J Med Genet. 1999;36:97-102.

6. Peltoketo H, Luu-The V, Simard J, et al. 17beta-hydroxysteroid dehydrogenase (HSD)/17-ketosteroid reductase (KSR) family; nomenclature and main characteristics of the 17HSD/KSR enzymes. J Mol Endocrinol. 1999;23:1-11.

7. Adamski J, Jakob FJ. A guide to 17beta-hydroxysteroid dehydrogenases. Mol Cell Endocrinol. 2001;171:1-4.

8. Oduwole OO, Isomaa VV, Nokelainen PA, et al. Downregulation of estrogen-metabolizing 17 beta-hydroxysteroid dehydrogenase type 2 expression correlates inversely with Ki67 proliferation marker in colon-cancer development. Int J Cancer. 2002;97:1-6.

9. Pettersson K, Gustafsson JA. Role of estrogen receptor beta in estrogen action. Annu Rev Physiol. 2001;63:165-192.
10. Jakacka M, Ito M, Weiss J, et al. Estrogen receptor binding to DNA is not required for its activity through the nonclassical AP1 pathway. J Biol Chem. 2001;276:13615-13621.

11. Paech K, Webb P, Kuiper GG, et al. Differential ligand activation of estrogen receptors ERalpha and ERbeta at AP1 sites. Science. 1997:277:1508-1510.

12. Roger P, Sahla ME, Makela S, et al. Decreased expression of estrogen receptor beta protein in proliferative preinvasive mammary tumors. Cancer Res. 2001;61:2537-2541.

13. Horvath LG, Henshall SM, Lee CS, et al. Frequent loss of estrogen receptor-beta expression in prostate cancer. Cancer Res. 2001; 61:5331-5335.

14. Wingo PA, Ries LA, Rosenberg HM, et al. Cancer incidence and mortality, 1973-1995: a report card for the U.S. Cancer. 1998; 82:1197-1207.

15. Kampman E, Potter JD, Slattery ML, et al. Hormone replacement therapy, reproductive history, and colon cancer: a multicenter, casecontrol study in the United States. Cancer Causes Control. 1997; $8: 146-158$

16. Nanda K, Bastian LA, Hasselblad V, et al. Hormone replacement therapy and the risk of colorectal cancer: a meta-analysis. Obstet Gynecol. 1999;93:880-888.

17. Campbell-Thompson M, Lynch IJ, Bhardwaj B. Expression of estrogen receptor (ER) subtypes and ERbeta isoforms in colon cancer. Cancer Res. 2001;61:632-640.

18. Waliszewski P, Blaszczyk M, Wolinska-Witort E, et al. Molecular study of sex steroid receptor gene expression in human colon and in colorectal carcinomas. J Surg Oncol. 1997;64:3-11.

19. Foley EF, Jazaeri AA, Shupnik MA, et al. Selective loss of estrogen receptor beta in malignant human colon. Cancer Res. 2000;60: 245-248.

20. Witte D, Chirala M, Younes A, et al. Estrogen receptor beta expressed in human colorectal adenocarcinoma. Hum Pathol. 2001; 32:940-944.

21. Livak KJ, Schmittgen TD. Analysis of relative gene expression data using real-time quantitative PCR and the 2[-Delta Delta C(T)] Method. Methods. 2001;25:402-408.

22. Issa JP, Ottaviano YL, Celano P, et al. Methylation of the oestrogen receptor $\mathrm{CpG}$ island links ageing and neoplasia in human colon. Nat Genet. 1994;7:536-540.

23. Xie LQ, Yu JP, Luo HS. Expression of estrogen receptor beta in human colorectal cancer. World J Gastroenterol. 2004;10:214-217.

24. Mosselman S, Polman J, Dijkema R. ER beta: identification and characterization of a novel human estrogen receptor. FEBS Lett. 1996;392:49-53.

25. Moore JT, McKee DD, Slentz-Kesler K, et al. Cloning and characterization of human estrogen receptor beta isoforms. Biochem Biophys Res Commun. 1998;247:75-78.

26. Peng B, Lu B, Leygue E, et al. Putative functional characteristics of human estrogen receptor-beta isoforms. J Mol Endocrinol. 2003; 30:13-29.

27. Schmitt CA, Fridman JS, Yang M, et al. Dissecting p53 tumor suppressor functions in vivo. Cancer Cell. 2002;1:289-298.

28. Konstantinopoulos PA, Kominea A, Vandoros G, et al. Oestrogen receptor beta is abundantly expressed in normal colonic mucosa, but declines in colon adenocarcinoma paralleling the tumor's dedifferentiation. Eur J Cancer. 2003;39:1251-1258.

29. Oduwole OO, Li Y, Isomaa VV, et al. 17beta-hydroxysteroid dehydrogenase type 1 is an independent prognostic marker in breast cancer. Cancer Res. 2004;64:7604-7609.

30. Russo J, Russo IH. The role of estrogen in the initiation of breast cancer. J Steroid Biochem Mol Biol. 2006;102:89-96. 